\title{
Neurotransmissions of antidepressant-like effects of kisspeptin-13
}

M. ${ }^{\mathrm{a}}$ Tanaka, K${ }^{\cdot \mathrm{b}}$ Csabafi and G. ${ }^{\mathrm{a}}$ bTelegdy

${ }^{b}$ Department of Pathophysiology, ${ }^{\mathrm{a}}$ Neuroscience Research Group of the Hungarian Academy of Science, Faculty of Medicine, University of Szeged, Szeged, Hungary

Corresponding author: Gyula Telegdy

Semmelweis 1, Szeged, Hungary

Tel.: 3662545797

Fax: 3662545710

Email: telegdy@patph.szote.u-szeged.hu

\begin{abstract}
Kisspeptins are $\mathrm{G}$ protein-coupled receptor ligands originally identified as human metastasis suppressor gene products that have the ability to suppress melanoma and breast cancer metastasis and recently found to have an important role in initiating secretion of gonadotropin-releasing hormone $(\mathrm{GnRH})$ at puberty. In the brain the gene is transcribed within the hippocampal dentate gyrus. Kisspeptin-13 is one of endogenous isoforms that consists of 13 amino acids. Antidepressive-like effects of kisspeptin-13 was studied and the involvement of the adrenergic, serotonergic, cholinergic, dopaminergic or gabaergic receptors in its antidepressant-like effect was investigated in modified forced swimming test (FST) in mice. Mice were pretreated with a non-selective $\alpha$-adrenergic receptor antagonist phenoxybenzamine, an $\alpha 1 / \alpha 2 \beta$-adrenergic receptor antagonist, prazosin, an $\alpha 2$-adrenergic receptor antagonist, yohimbine, a $\beta$-adrenergic receptor antagonist, propranolol, a mixed 5HT1/5-HT2 serotonergic receptor antagonist, methysergide, a non-selective 5HT2 serotonergic receptor antagonist, cyproheptadine, nonselective muscarinic acetylcholine
\end{abstract}


receptor antagonist, atropine, D2,D3,D4 dopamine receptor antagonist, haloperidol or $\gamma$ aminobutyric acid subunit A (GABAA) receptor antagonist, bicucullin.

FST showed that kisspeptin-13 reversed the immobility, climbing and swimming times, suggesting antidepressant-like effects. Phenoxybenzamine, yohimbine and cyproheptadine prevented the effects of kisspeptin-13 on the immobility, climbing and swimming time. Prazosin, propranolol, methysergide, atropine, haloperidol and bicucullin did not change the effects of kisspeptin-13.

The results demonstrated that the antidepressant-like effect of kisspeptin-13 is mediated, at least in part, by an interaction of the $\alpha_{2}$-adrenergic and 5-HT 2 serotonergic receptors in a modified mouse FST.

Keywords: Kisspeptins; Kisspeptin-13; Receptors; Depression

\section{Introduction}

Kisspeptin, formerly known as metastin was originally identified as a human metastasis suppressor that inhibits metastasis of melanoma and breast cancer [1]. This G proteincoupled receptor ligand was recently found to have an important role in initiating secretion of gonadotropin-releasing hormone $(\mathrm{GnRH})$ at puberty [2]. In central nervous system kisspeptin is transcribed within the hippocampal dentate gyrus. Kisspeptin-13 is one of endogenous isoforms that consists of 13 amino acids [3]. However, little is know about the machanisms and pathways of kisspeptin-13 on brain functions.

Antidepressive-like effects of kisspeptin-13 was studied and the involvement of the adrenergic, serotonergic, cholinergic, dopaminergic or gabanergic receptors in its antidepressant-like effect was investigated in modified forced swimming test (FST) in mice. Mice were pretreated with a non-selective $\alpha$-adrenergic receptor antagonist 
phenoxybenzamine, an $\alpha_{1} / \alpha_{2 \beta}$-adrenergic receptor antagonist, prazosin, an $\alpha_{2}$-adrenergic receptor antagonist, yohimbine, a $\beta$-adrenergic receptor antagonist, propranolol, a mixed 5$\mathrm{HT}_{1} / 5-\mathrm{HT}_{2}$ serotonergic receptor antagonist, methysergide, a non-selective 5-

$\mathrm{HT}_{2}$ serotonergic receptor antagonist, cyproheptadine, nonselective muscarinic acetylcholine receptor antagonist, atropine, $\mathrm{D}_{2}, \mathrm{D}_{3}, \mathrm{D}_{4}$ dopamine receptor antagonist, haloperidol or $\gamma$ aminobutyric acid subunit $\mathrm{A}\left(\mathrm{GABA}_{\mathrm{A}}\right)$ receptor antagonist, bicucullin.

\section{Materials and methods}

\subsection{Animals}

CFLP male mice were kept and handled during the experiments in accordance with the instructions of the University of Szeged Ethical Committee for the Protection of

Animals in Research. Each animal was used in the experiments only once. The animals were housed in cages in a room maintained at constant temperature $\left(25 \pm 1{ }^{\circ} \mathrm{C}\right)$ and on a 12 -h darklight cycle (lights on at 06:00-18:00 h) with free access to tap water and standard laboratory food. At least 1 week of recovery from surgery was allowed before the experiments.

\subsection{Surgery}

The mice were implanted with a cannula introduced into the right lateral brain ventricle in order to allow intracerebroventricular (i.c.v.) administration. The polystyrene cannula was inserted stereotaxically into the ventricle at the coordinates $0.2 \mathrm{~mm}$ posterior, $0.2 \mathrm{~mm}$ lateral to the bregma, and $2.0 \mathrm{~mm}$ deep from the dural surface [4]. The cannula was secured with cianoachrilate (Ferrobond) (Budapest, Hungary). The mice were allowed a minimum of 5 days to recover from surgery before any i.c.v. administration.

\subsection{Materials}


Kisspeptin-13 was from Bachem (Basel Switzerland). Phenoxybenzamine hydrochloride was obtained from Smith Kline \& French (Herts, UK); prazosin hydrochloride fromTocris (); yohimbine hydrochloride from Tocris (Cologne, Germany); propranolol hydrochloride from ICI Ltd. (Macclesfield, UK); methysergide hydrogen maleate from Sandoz (Cologne, Germany); cyproheptadine hydrochloride from Tocris (Bristol, UK); atropine sulphate from EGYS (Budapest, Hungary); haloperidol from G. Richter (Budapest, Hungary); and bicuculline methiodide from Sandoz (Basle, Switzerland).

Kisspeptin-143 was lyophilized in a quantity of $10 \mu \mathrm{g}$ per ampoule and stored at $-20{ }^{\circ} \mathrm{C}$. Immediately before the experiments. kisspeptin-143 was dissolved in sterile pyrogen-free $0.9 \%$ saline and administered i.c.v. via the cannula in a volume of $2 \mu \mathrm{l}$.

\subsection{Forced swimming test}

The modified mouse FST was conducted as reported previously [5,6]. The mice were forced to swim individually in a glass cylinder $12 \mathrm{~cm}$ in diameter and $30 \mathrm{~cm}$ in height, filled with water to a height of $20 \mathrm{~cm}$. The temperature of the water was adjusted to $25 \pm 1 \mathrm{C}$. The water was changed between the individual mice. A $15 \mathrm{~min}$ pretest session was followed $24 \mathrm{~h}$ later by a $5 \mathrm{~min}$ test session. Phenoxybenzamine (2mg/kg,i.p.), prazosin $(62.5 \mu \mathrm{g} / \mathrm{kg}$,i.p.), yohimbine (5mg/kg,i.p.),propranolol (5mg/kg, i.p.), methysergide (5mg/kg, i.p.), cyproheptadine (3mg/kg, i.p.), atropine ( $2 \mathrm{mg} / \mathrm{kg}$, i.p.), haloperidol $(10 \mu \mathrm{g} / \mathrm{kg}$, i.p.) or bicuculline $(2 \mathrm{mg} / \mathrm{kg}$, i.p.) were administered $1 \mathrm{~h}$ before the test session followed30min later by kisspeptin $(2.0 \mu \mathrm{g} / 2$ $\mu$ l, i.c.v.) [7-12]. Physiological saline was used as vehicle control. A time-sampling technique was applied to score the durations of climbing, swimming and immobility. Climbing time was measured when the mouse was participating inactive vertical motion with its forelegs above the water level; swimming time was recorded when the mouse was moving in horizontally on the surface of the water; and immobility time was registered when the 
mouse was in a upright position on the surface with its front paws together and making only those movements necessary to keep itself afloat.

\subsection{Statistical analysis}

The analysis of variance (ANOVA) test was followed by Tukey's test for multiple comparisons with unequal cell size. Probability values $(\mathrm{P})$ of less than 0.05 were regarded as indicative of significant differences.

\section{Results}

Kisspeptin-13 $(2.0 \mu \mathrm{g} / 2 \mu \mathrm{l})$-administered mice exhibited a significantly decreased immobility time $[F(3.35)=14.98: P<0.05]$, a significantly increased climbing time

$[F(3.35)=7.75: P<0.05]$ and a significantly increased swimming time

$[F(3.35)=11.10: P<0.05]($ Fig. 1$)$

Phenoxybenzamine per se $(2 \mathrm{mg} / \mathrm{kg})$ did not affect the immobility time, climbing time, or swimming time. In kisspeptin-13-treated mice, pretreatment with phenoxybenzamine partially reversed the kisspeptin-13-induced change in the immobility time, and decreased the changes in the climbing and swimming times (Fig. 2).

Prazosin per se $(62.5 \mu \mathrm{g} / \mathrm{kg}$, i.p. $)$ did not affect the immobility time, the climbing time or the swimming time. In kisspeptin-13-treated mice, pretreatment with prazosin did not reverse the kisspeptin-13-induced change in the immobility time, climbing time and the swimming time (data not shown).

Yohimbine per se $(5 \mathrm{mg} / \mathrm{kg}$, i.p.) did not affect the immobility time, the climbing time, or the swimming time. In kisspeptin-13-treated mice, pretreatment with yohimbine partially reversed the immobility time, climbing time and the swimming time (Fig. 3).

Methysergide per se (5mg/kg, i.p.) did not affect the immobility time, the climbing time or the swimming time. In kisspeptin-13-treated mice, pretreatment with methysergide did not reverse immobility time, the climbing time and the swimming time (data not shown). 
Cyproheptadine per se (3mg/kg, i.p.) did not affect the immobility time, the climbing time or the swimming time. In kisspeptin-13-treated mice, pretreatment with cyproheptadine resulted in an increased immobility time and decreased the changes

in the climbing and the swimming times (Fig. 4).

Propranolol per se $(5 \mathrm{mg} / \mathrm{kg}$, i.p.) did not affect the immobility time, the climbing time, or the swimming time. In kisspeptin-13- treated mice time, pretreatment with propranolol did not lead to an increase in the immobility time, and did not affect the climbing time ort he swimming time (data not shown).

Atropine per se $(2 \mathrm{mg} / \mathrm{kg}$, i.p.) did not affect the immobility time, the climbing time, or the swimming time. In kisspeptin-13-treated mice, pretreatment with atropine did not affect the increased immobility time and the decreased climbing and the swimming times (data not shown).

Haloperidol per se $(10 \mu \mathrm{g} / \mathrm{kg}$, i.p.) did not affect the immobility time, the climbing time, or the swimming time. In kisspeptin-13-treated mice, pretreatment with haloperidol did not increase the immobility time nor affect the climbing or the swimming times (data not shown).

Bicuculline per se $(2 \mathrm{mg} / \mathrm{kg}$, i.p.) did not affect the immobility time, the climbing time or the swimming time. In kisspeptin-13-treated mice pretreatment with bicuculline did not increase the immobility time, or the climbing time, or the swimming time (data not shown).

The above results reveal that the antidepressant-like effect of kisspeptin-13 is mediated, at least in part, by $\alpha_{2}$-adrenergic receptors and 5- $\mathrm{HT}_{2}$ serotonergic receptors in a modified mouse FST.

\section{Discussion}

In the central nervous system kisspeptin expressing neurons are located in the anteroventral periventricular nucleus (AVPV), perventricular nucleus (PVN), anterodorsal preoptic nucleus (ADP) and arcuate nuceus (Arc) [13]. In a close relationship to PVN, the neurons of AVPV 
and Arc project fibers into the preoptic area rich in $\mathrm{GnRH}$ cell bodies. It is now known that kisspeptin stimulates the secretion of GnRH which is sensitive to steroid levels [14]. The previous studies showed that luteinizing hormone releasing hormone (LHRH) antagonist, cetrorelix and growth hormone releasing hormone (GHLH) antagonist kisspeptin-13 have antidepressant-like effects in a modified mice FST, suggesting close relationships between growth hormone reguation and mood disorders alleviation $[15,16,17,18]$.

Kisspeptin-13 is one of endogenous kisspeptin isoforms that consists of 13 amino acids. In this study kisspeptin-13 display antidepressnat-like effects in a modified FST.

To clarify the mechanism of the antidepressant-like actions of kisspeptin-13, various receptor blockers were applied berfore kisspeptin-13 administration. The doses of receptor blockers were selected so that blockers per se were ineffective but were able to block the action of a neuropeptide as describe in the previous study [19]. The obervation with receptor blockers indicates that the action of kisspeptin-13 is mediated by certain receptors.

The results indicated a non-selective $\alpha$-adrenergic receptor antagonist, phenoxybenzamine, an $\alpha_{2}$-adrenergic receptor antagonist, yohimbine and a non-selective $5-\mathrm{HT}_{2}$ serotonergic receptor antagonist, cyproheptadine prevented the effects of kisspeptin-13 on the immobility, climbing and swimming time. an $\alpha_{1} / \alpha_{2 \beta}$-adrenergic receptor antagonist, prazosin, a $\beta$-adrenergic receptor antagonist, propranolol, a mixed $5-\mathrm{HT}_{1} / 5-\mathrm{HT}_{2}$ serotonergic receptor antagonist, methysergide, a nonselective muscarinic acetylcholine receptor antagonist, atropine, $D_{2}, D_{3}, D_{4}$ dopamine receptor antagonist, haloperidol and $\gamma$-aminobutyric acid subunit $\mathrm{A}\left(\mathrm{GABA}_{\mathrm{A}}\right)$ receptor antagonist, bicucullin did not change the effects of kisspeptin-13.

The results demonstrated that the antidepressant-like effect of kisspeptin-13 is mediated, at least in part, by an interaction of the $\alpha_{2}$-adrenergic and 5- $\mathrm{HT}_{2}$ serotonergic receptors in a modified mouse FST.

Acknowledgments

This work was supported by grants from ETT (008/2003) and RET (08/2004). 


\section{References}

[1] JF. Harms, DR. Welch, ME. Miele. KISS1 metastasis suppression and emergent pathways. Clin Exp Metastasis. 20 (1) (2003), pp.11-18.

[2] HM. Dungan, DK. Clifton, RA. Steiner. Minireview: kisspeptin neurons as central processors in the regulation of gonadotropin-releasing hormone secretion.

Endocrinology. 147 (3) (2006), pp. 1154-1158.

[3] K. Tsutsui, GE. Bentley, LJ. Kriegsfeld, T. Osugi, JY. Seong, H. Vaudry. Discovery and evolutionary history of gonadotrophin-inhibitory hormone and kisspeptin: new key neuropeptides controlling reproduction. J Neuroendocrinol. 22 (7) (2010), pp. 716-27.

[4] A.S. Pellergrino and A.J. Cushman, Stereotaxic Atlas of the Rat Brain, Plenum Press, New York (1979), pp. 8-57.

[5] M.J. Detke, M. Rickels and I. Lucki, Active behaviors in the rat forced swimming test differentially produced by serotonergic and noradrenergic antidepressants.

Psychopharmacology (Berl). 121 (1) (1995), pp. 66-72.

[6] R.T. Khisti, C.T. Chopde and S.P. Jain, Antidepressant-like effect of the neurosteroid 3alpha-hydroxy-5alpha-pregnan-20-one in mice forced swim test, Pharmacol. Biochem. Behav. 67 (1) (2000), pp. 137-143.

[7] D. Consoli, G.M. Leggio, C. Mazzola, V. Micale and F. Drago, Behavioral effects of the beta3 adrenoceptor agonist SR58611A: is it the putative prototype of a new class of antidepressant/anxiolytic drugs? Eur. J. Pharmacol. 573 (1-3) (2007), pp. 139-147.

[8] D. Dhingra and A. Sharma, Antidepressant-like activity of $n$-hexane extract of nutmeg (Myristica fragrans) seeds in mice. J. Med. Food. 9 (1) (2006), pp. 84-89.

[9] A. Dhir and S.K. Kulkarni, Effect of addition of yohimbine (alpha-2-receptor antagonist) to theantidepressant activity of fluoxetine or venlafaxine in the mouse forced swim test. Pharmacology. 80 (4) (2007), pp. 239-243. 
[10] A. Dias Elpo Zomkowski, A. Oscar Rosa, J. Lin, A.R. Santos, J.B. Calixto and A. Lúcia Severo Rodrigues. Evidence for serotonin receptor subtypes involvement in agmatine antidepressant like-effect in the mouse forced swimming test. Brain Res. 1023 (2) (2004), pp. 253-263.

[11] S. Evangelista, F. Borsini and A. Meli, Evidence that muscimol acts in the forced swimming test by activating the rat dopaminergic system, Life Sci. 41 (24) (1987), pp. 2679-2684 .

[12] V. Reny-Palasse and R. Rips, Potentiation by TRH of the effect of imipramine on the forced-swimming test, Br. J. Pharmacol. 85 (2) (1985), pp. 463-470.

[13] JD. Mikkelsen, V. Simonneaux. The neuroanatomy of the kisspeptin system in the mammalian brain. Peptides. 30 (1) (2009), pp. 26-33.

[14] J. Roa, VM. Navarro, M. Tena-Sempere. Kisspeptins in reproductive biology: consensus knowledge and recent developments. Biol Reprod. 85 (4) (2011), pp. 650-660.

[15] G. Telegdy, M. Tanaka, A.V. Schally .Effects of the LHRH antagonist Cetrorelix on the brain function in mice. Neuropeptides. 43(3) (2009), pp. 229-234.

[16] G. Telegdy, A. Adamik, M. Tanaka, A.V. Schally, Effects of the LHRH antagonist Cetrorelix on affective and cognitive functions in rats. Regul Pept. 159 (1-3) (2010), pp. 142-147.

[17] G. Telegdy, M. Tanaka, A.V. Schally. Effects of the growth hormone-releasing hormone (GH-RH) antagonist on brain functions in mice. Behav Brain Res. 224 (1) (2011), pp. 155-158.

[18] M. Tanaka, AV. Schally, G. Telegdy. Neurotransmission of the antidepressant-like effects of the growth hormone-releasing hormone antagonist MZ-4-71. Behav Brain Res. 228 (2) (2012), pp. 388-391. 
[19] G. Telegdy , H. Tiricz, A. Adamik. Involvement of neurotransmitters in urocortininduced passive avoidance learning in mice. Brain Res Bull. 67 (3) (2005), pp. 242-247. 


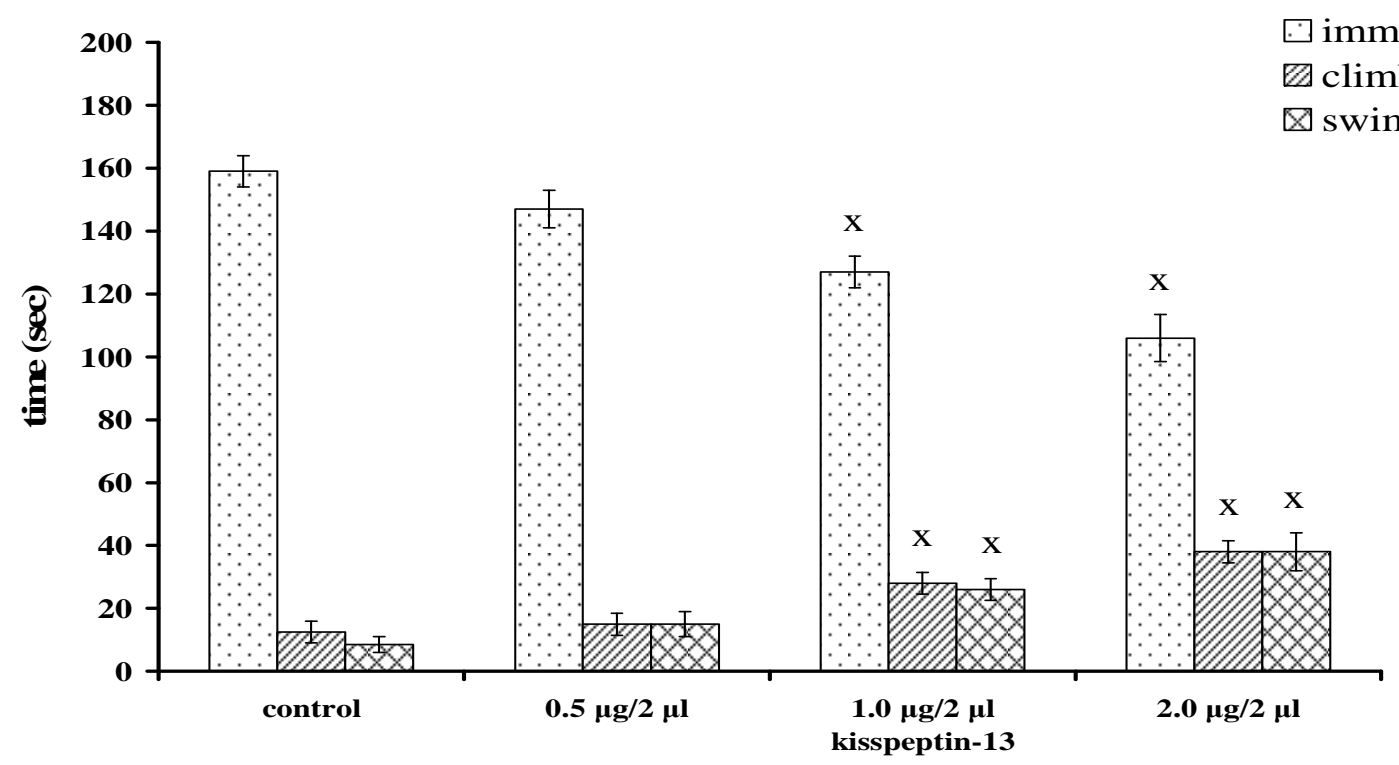

Figure 1. The antidepressant-like effects of kisspeptin-13 in modified mouse forced swim test (FST).

Control $(N=12)$, kisspeptin-13 $0.5 \mu \mathrm{g} / 2 \mu$ l, i.c.v. $(N=6)$, kisspeptin-13 $1.0 \mu \mathrm{g} / 2 \mu \mathrm{l}$, i.c.v. $(N=12)$, kisspeptin-13 $2.0 \mu \mathrm{g} / 2 \mu$ l, i.c.v. $(N=5) . \mathrm{x}: P<0.05 \mathrm{vs.}$ control $(N$ : the number of animals, $P$ : probability). 


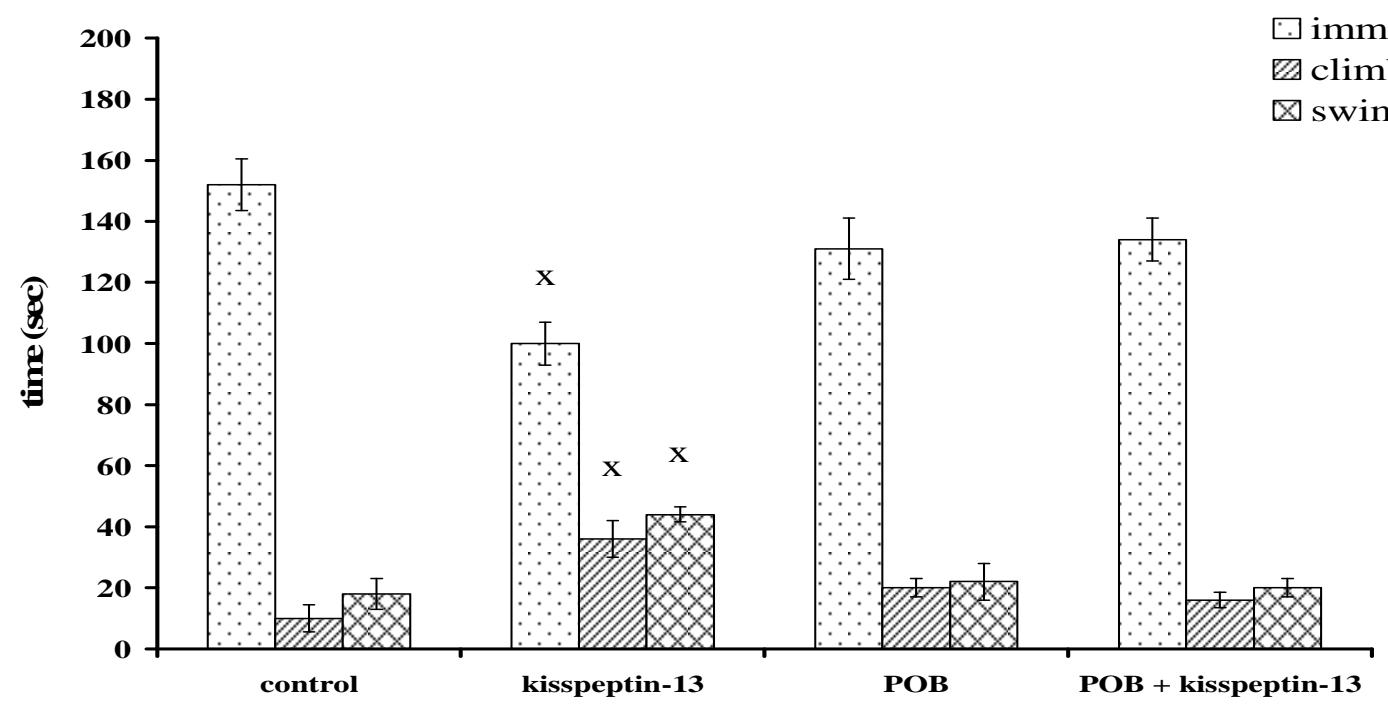

Figure 2. The effect of a nonselective $\alpha$-adrenergic receptor antagonist, phenoxybenzamine (POB) in kisspeptin-13-induced antidepressant-like action in modified mouse forced swim test (FST).

Control ( $N=5$ ), kisspeptin-13 $2.0 \mu \mathrm{g} / 2 \mu$ l, i.c.v. $(N=5)$, Phenoxybenzamine (POB) $2.0 \mathrm{mg} / \mathrm{kg}$, i.p. $(N=5)$, Phenoxybenzamine (POB) $2.0 \mathrm{mg} / \mathrm{kg}$, i.p. + kisspeptin-13 $2.0 \mu \mathrm{g} / 2 \mu$ l, i.c.v. $(N=5)$. x: $P<0.05$ vs. control ( $N$ : the number of animals, $P$ : probability). 


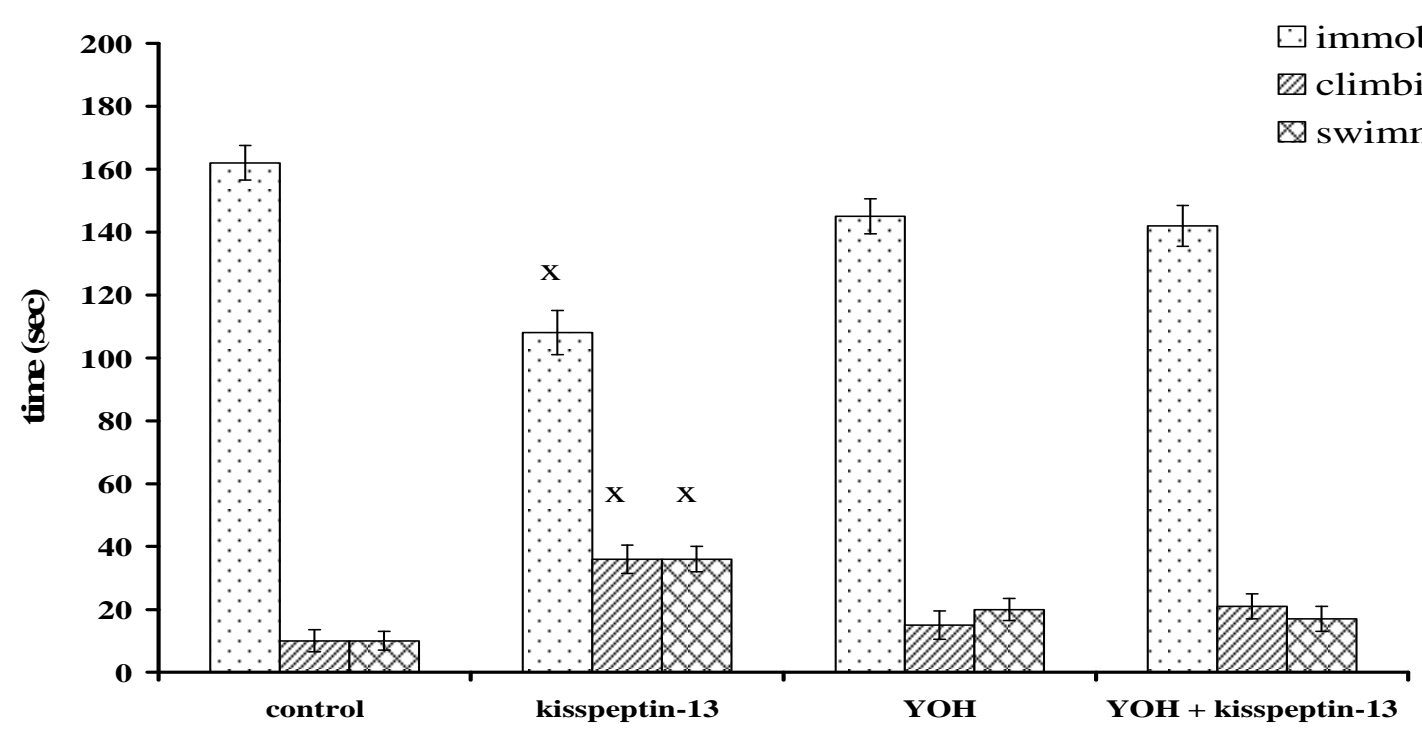

Figure 3. The effect of a nonselective $\alpha$-adrenergic receptor antagonist, yohimbine (YOH) in kisspeptin-13-induced antidepressant-like action in modified mouse forced swim test (FST).

Control $(N=10)$, kisspeptin-13 $2.0 \mu \mathrm{g} / 2 \mu$ l, i.c.v. $(N=10)$, yohimbine (YOH) $5.0 \mathrm{mg} / \mathrm{kg}$, i.p. $(N=10)$, yohimbine $(\mathrm{YOH}) 5.0 \mathrm{mg} / \mathrm{kg}$, i.p. + kisspeptin-13 $2.0 \mu \mathrm{g} / 2 \mu$ l, i.c.v. $(N=10) . \mathrm{x}: P<$ 0.05 vs. control ( $N$ : the number of animals, $P$ : probability). 


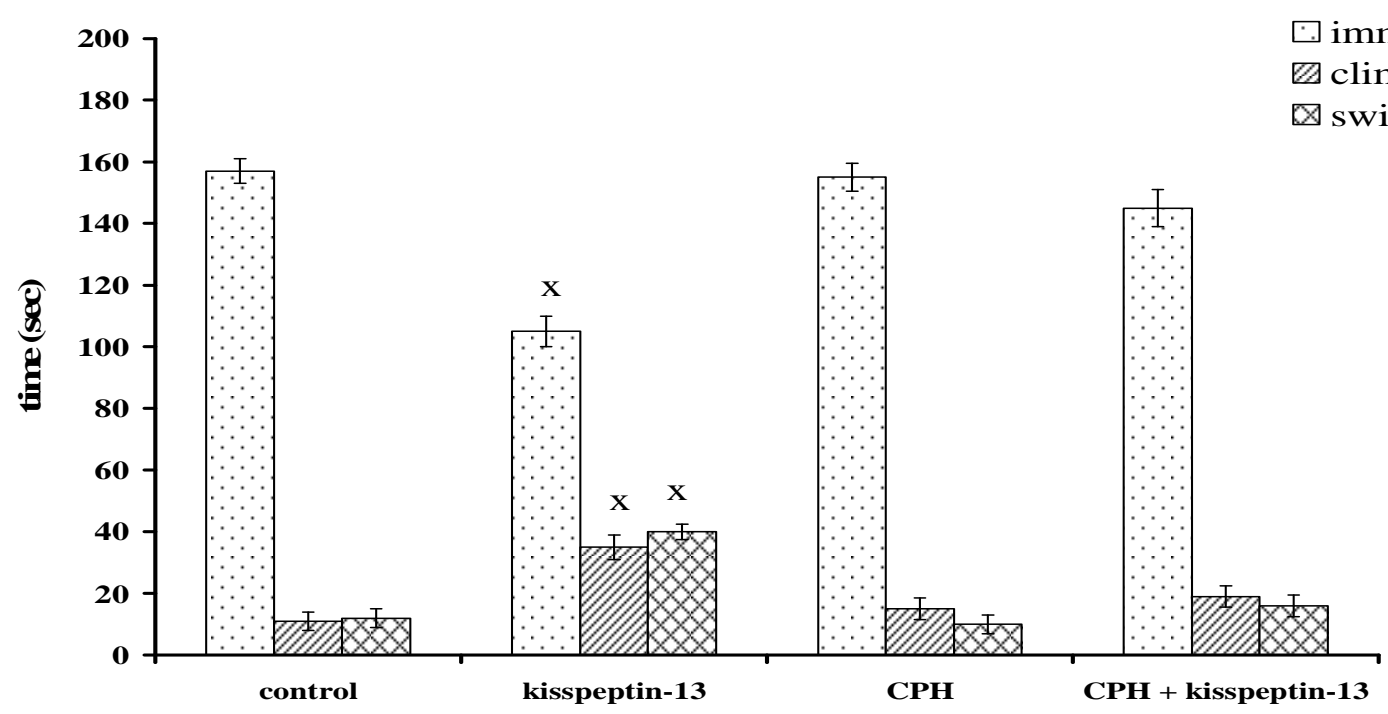

Figure 4. The effect of a nonselective 5-HT 2 serotonergic receptor antagonist, cyproheptadine (CPH) in kisspeptin-13-induced antidepressant-like action in modified mouse forced swim test (FST).

Control ( $N=14$ ), kisspeptin-13 $2.0 \mu \mathrm{g} / 2 \mu$ l, i.c.v. $(N=15)$, Cyproheptadine $(\mathrm{CPH}) 3.0 \mathrm{mg} / \mathrm{kg}$, i.p. $(N=15)$, Cyproheptadine (CPH) $3.0 \mathrm{mg} / \mathrm{kg}$, i.p. + kisspeptin-13 $2.0 \mu \mathrm{g} / 2 \mu$ l, i.c.v. $(N=15)$. $\mathrm{x}: P<0.05$ vs. control ( $N$ : the number of animals, $P$ : probability). 
